05

\title{
Механизм и динамика разрушения кальцита под влиянием ударной волны
}

\author{
() И.П. Щербаков, В.И. Веттегрень, Р.И. Мамалимов \\ Физико-технический институт им. А.Ф. Иофрфе РАН, \\ 194021 Санкт-Петербург, Россия \\ ฯ e-mail: Victor.Vettegren@mail.ioffe.ru
}

(Поступило в Редакцию 15 февраля 2017 г.)

Получены спектры люминесценции при разрушении кальцита под действием ударной волны, вызванной электрическим разрядом, и при трении. Их анализ показал, что механизмы разрушения при этих воздействиях различны. Под влиянием волны кристаллическая решетка кальцита распадается на положительно заряженные ионы кальция, углерода и кислорода. При трении кальцит разрушается путем накопления микротрещин. Величина объема, который распадается на ионы, зависит от энергии электрического разряда. Когда энергия составляет $\sim 80 \mathrm{~J}$, распадается более $60 \%$ объема кальцита. При энергии электрического разряда $0.2 \mathrm{~J}$ величина объема не превышает долей процента. В этом случае, как показали исследования временной зависимости люминесценции с разрешением $2 \mathrm{~ns}$, разрушение локализовано в границах кристаллических зерен.

DOI: $10.21883 /$ JTF.2017.10.44997.2206

\section{Введение}

В последние годы нами были начаты экспериментальные исследования механизма разрушения ненагруженных гетерогенных материалов - горных пород под воздействием ударных волн. Было установлено [1-6], что кристаллические решетки кварца и гранитов распадаются на положительно заряженные ионы. Настоящая работа продолжает цикл этих исследований. В ней изложены результаты изучения механизма разрушения кальцита.

\section{Объект и метод исследования}

Для исследований был выбран образец кальцита $\mathrm{CaCO}_{3}$ в виде круглой пластинки диаметром $30 \mathrm{~mm}$ и толщиной $8 \mathrm{~mm}$. С одной стороны пластинки пропилен паз глубиной и шириной $\sim 3 \mathrm{~mm}$. В нем располагались медные электроды, расстояние между которыми $\sim 3 \mathrm{~mm}$. Они соединены с конденсатором, при разряде которого в промежутке между двумя медными проводниками образуется плазма, состоящая из микрочастиц и атомов $\mathrm{Cu}$ [7]. Она вызывает появление в кальците ударной волны. Под ее воздействием часть образца разлагается на положительно заряженные ионы, которые вылетали из образца в виде струи плазмы.

Было проведено две серии экспериментов.

Цель первой заключалась в том, чтобы получить спектр плазмы. Установка, построенная для этой цели, описана в [1]. Конденсатор был заряжен до $2 \mathrm{kV}$, что соответствует запасенной энергии $80 \mathrm{~J}$. Оказалось, что при такой энергии более $60 \%$ объема образца распадалось на ионы, которые вылетали из образца в виде плазмы. Длина струи плазмы составляла $\sim 0.4 \mathrm{~m}$. Излучение плазмы через кварцевый световод подавали на входное окно спектрометра AvaSpec-ULS3648.
Спектр плазмы сравнивали со спектром излучения при трении кальцита. Установка для его получения описана в [8].

Временную зависимость интенсивности плазмы в таких условиях получить не удалось.

Во второй серии экспериментов исследовали временную зависимость интенсивности струи. С этой целью использовали установку, описанную в $[2,3]$. В ней электроды были присоединены к вторичной обмотке высоковольтного трансформатора, первичная обмотка которого соединена с конденсатором. После разряда конденсатора во вторичной обмотке трансформатора возникало высокое напряжение, которое приводило к разряду между электродами. Емкость конденсатора была подобрана таким образом, чтобы за время измерения разряд не приводил к заметному в оптический микроскоп изменению строения поверхности пластинки. Как показали предварительные измерения, энергия разряда, удовлетворяющая такому условию, составляет $\sim 0.2 \mathrm{~J}$. Излучение струи ионов через кварцевый световод подавали на поверхность фотокатода фотоэлектронного умножителя РМТ-136.

Разряд приводил к колебаниям пластинки кальцита. Их регистрировали, используя датчик из пьезокерамики CTS-19 (размеры датчика - $4 \times 4 \times 1 \mathrm{~mm}$ ).

Напряжения на пьезокерамике и выходе РМТ-136 подавали на вход аналогового цифрового преобразователя ADS-3112 и через каждые 2 ns записывали в память компьютера для дальнейшего анализа и обработки.

\section{Структура исследованного образца}

На рис. 1 показана фотография поверхности исследованного образца. Видно, что на ней наблюдаются зерна кальцита, линейный размер которых варьирует от $\sim 1$ до 


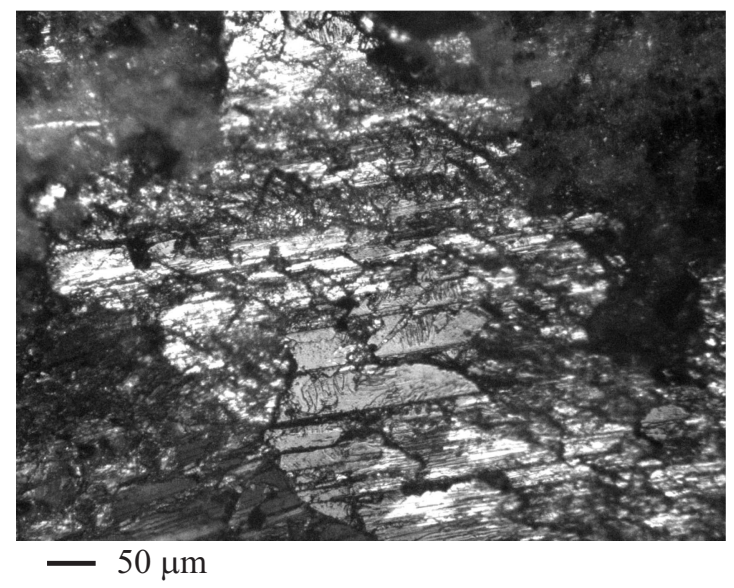

Рис. 1. Фотография поверхности пластинки из кальцита.

$\sim 100 \mu \mathrm{m}$. Анализ нескольких таких фотографий показал, что средний размер зерен составляет $\sim 30-50 \mu \mathrm{m}$.

\section{Спектр плазмы, вылетевшей из кальцита}

Спектр плазмы, вылетевшей с поверхности образца кальцита, состоит из нескольких десятков наложенных друг на друга узких линий (рис. 2).

Воспользовавшись таблицами спектральных линий [9], установили, что они соответствуют излучению одно-, дву- и трехкратно положительно заряженных ионов кальция, одно- и двукратно заряженных ионов углерода, кислорода и меди, а также однократно заряженных ионов азота. Ионы кальция, углерода и кислорода образовались при распаде кристаллической решетки кальцита, а меди - при испарении медных электродов. Ионы азота образовались в результате удара ионами плазмы по молекулам азота воздуха.

Для примера, одна из линий $-1.432 \mathrm{eV}-$ показана на рис. 3. Она соответствует излучению ионов $\mathrm{Ca}^{2+}$. Ee ширина (на половине максимальной интенсивности) - $2.2 \mathrm{meV}$. Ширина других линий варьировала от 1.5 до $2.5 \mathrm{meV}$. Линия смещена в сторону низких энергий на $\sim 2 \mathrm{meV}$ по сравнению со значением, приведенным в таблицах [9]. Смещение на $1-3 \mathrm{meV}$ наблюдалось также для линий углерода и кислорода. Этот эффект вызван взаимодействием между ионами в плазме (эффект Штарка) $[10]$.

Сравним спектр плазмы со спектром излучения кальцита при трении (рис. 4). В этом спектре наблюдается только один максимум $1.81 \mathrm{eV}$, уширенный в сторону высоких энергий. Он приписан отрицательно заряженным ион-радикалам $-\mathrm{C}=\mathrm{O}_{2}^{-}$, которые образуются при разрыве одной из связей $\mathrm{C}-\mathrm{O}-\mathrm{Ca}$ в кристаллической решетке кальцита [8]. Такие радикалы располагаются на берегах микротрещин [8], образующихся при трении. Ширина максимума $\sim 0.26 \mathrm{eV}$, т. е. на два порядка больше, чем в спектре плазмы.
Сравнение приведенных на рис. 2 и 4 спектров показывает, что механизмы разрушения под действием ударной волны и трения различны. Если при трении кальцит

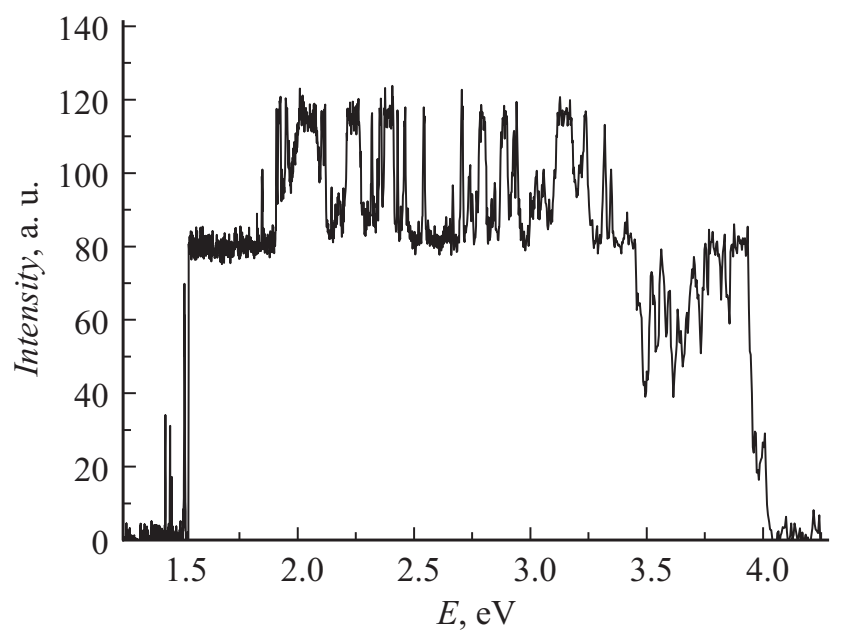

Рис. 2. Спектр излучения кальцита, под влиянием ударной волны.

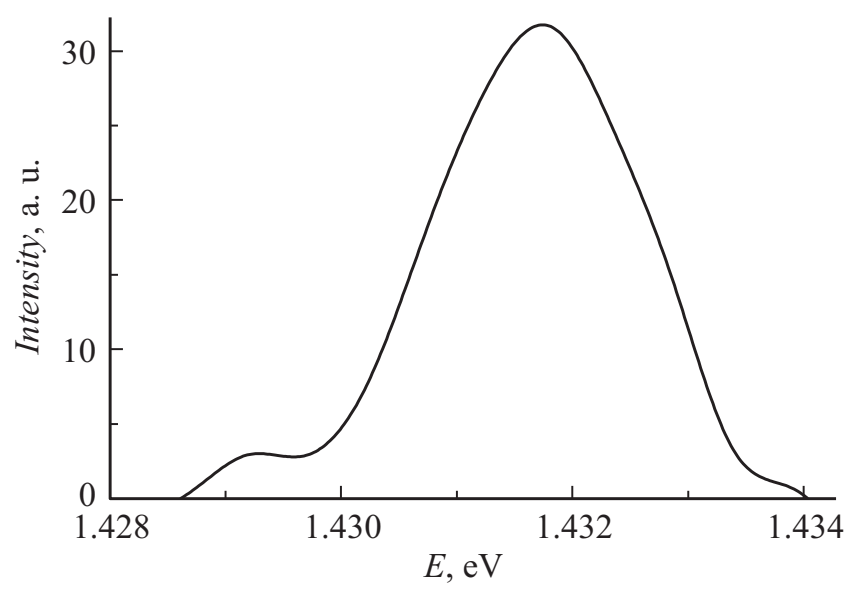

Рис. 3. Линия $1.432 \mathrm{eV}$ ионов $\mathrm{Ca}^{2+}$ в спектре излучения плазмы, вылетевшей из кальцита.

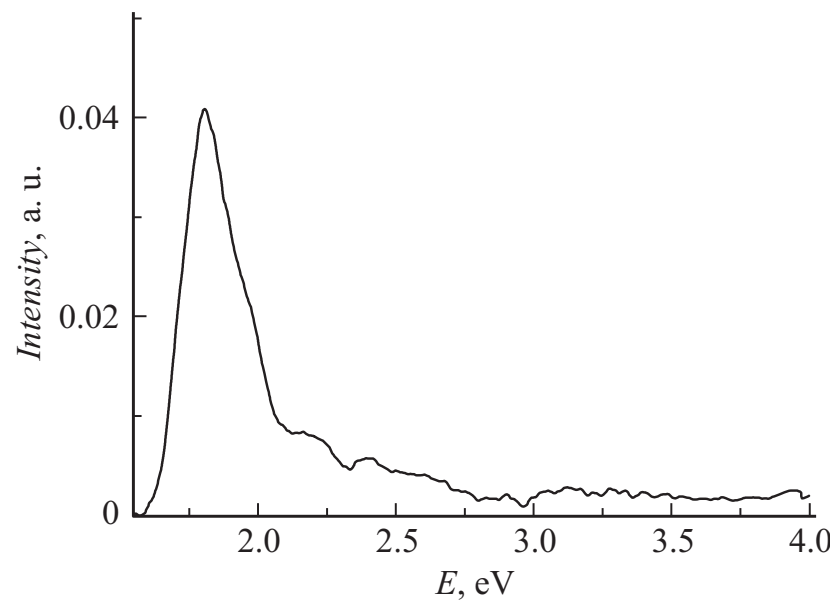

Pис. 4. Спектр люминесценции при трении кальцита. 
разрушается путем рождения и накопления микротрещин, то воздействие ударной волны вызывает распад кристаллической решетки на положительно заряженные ионы.

В работах $[11,12]$ был предложен механизм разрушения, не связанный с трещинами. Авторы показали, что сильные искажения кристаллической решетки могут приводить к переходам между электронными уровнями и распаду межатомных связей с образованием положительно заряженных ионов. Вероятно, большая деформация кристаллической решетки в поле ударной волны и приводит к ее распаду.

\section{Динамика разрушения}

Как уже отмечалось выше, для исследования временной зависимости интенсивности плазмы мощность, подводимая к конденсатору, была уменьшена в 400 раз - с 80 до 0.2 J. Однако и в этом случае из кальцита выделялась струя ионов.

Временная зависимость интенсивности излучения образца показана на рис. 5. Она является суммой двух зависимостей: излучения разряда, которое проникает через полупрозрачный образец кальцита, и излучения струи ионов, вылетающих с его поверхности.

Чтобы разделить их, рассмотрим начальный участок временной зависимости интенсивности света - от 0 до $2 \mu$ s (рис. 6). Видно, что интенсивность излучения на этом участке осциллирует. Осцилляции вызваны тем, что первичная обмотка трансформатора и конденсатор образуют колебательный контур. Осцилляции тока в нем приводят к осцилляциям интенсивности разряда. Эти осцилляции заканчиваются одновременно с окончанием разряда - через $\sim 1.5 \mu \mathrm{s}$.

При времени больше $1.5 \mu$ s основной вклад в излучение дают положительно заряженные ионы плазмы.

Рассмотрим временную зависимость излучения плазмы более подробно. Обращает на себя внимание, что оно

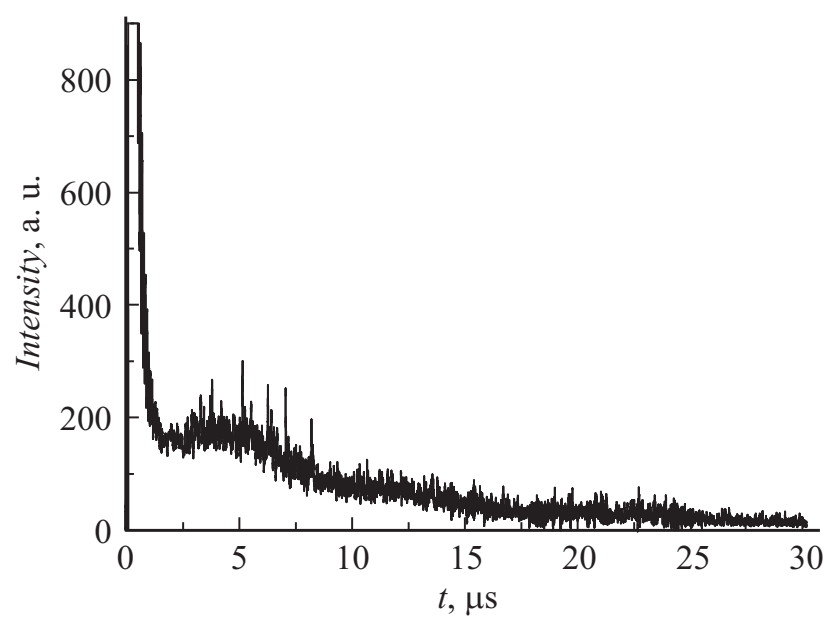

Рис. 5. Временная зависимость интенсивности излучения струй ионов из кальцита.

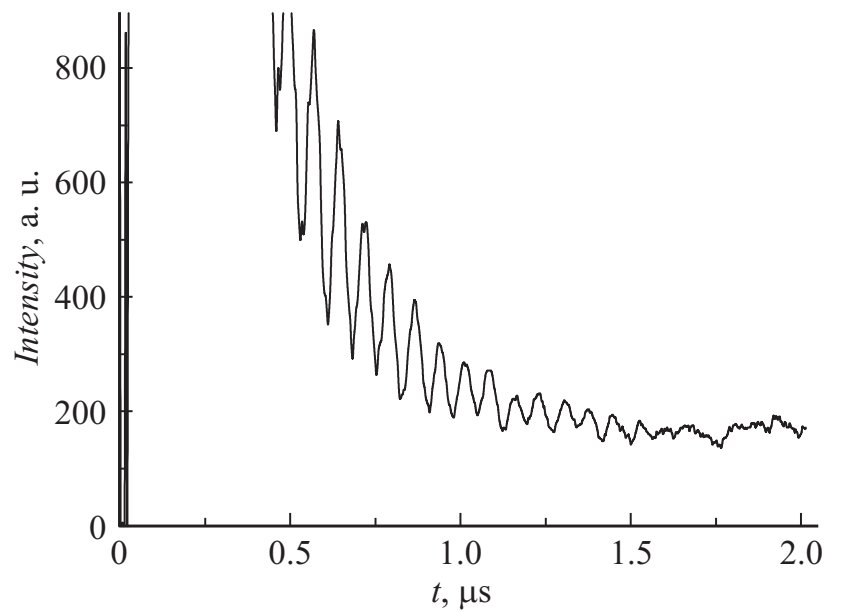

Рис. 6. Фрагмент временной зависимости излучения кальцита в диапазоне от 0 до $2 \mu \mathrm{s}$.

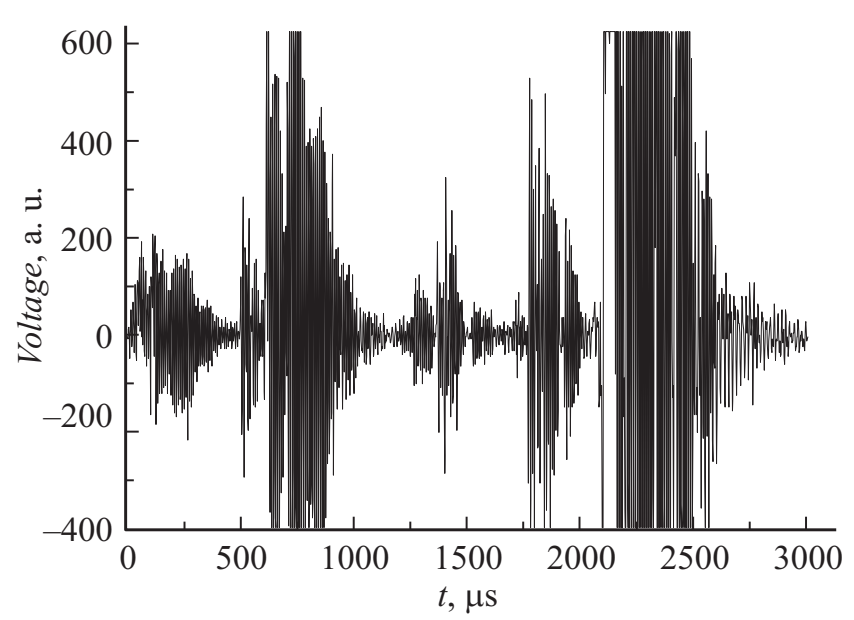

Рис. 7. Временная зависимость напряжения на пъезоэлементе.

продолжается более $30 \mu \mathrm{s}$, т.е. на порядок больше, чем горит разряд.

Чтобы выяснить причины столь длительного излучения, обратимся к рис. 7, на котором показана временная зависимость напряжения на пьезокерамическом датчике, установленном на поверхности образца. Видно, что под действием ударной волны пластинка кальцита начинает колебаться. Эти колебания продолжаются в течение времени, достигающего $3000 \mu \mathrm{s}$, т.е. на три порядка больше времени горения разряда. По-видимому, длительное существование этих колебаний вызвано многократными отражениями ударной волны от поверхностей образца. При таких отражениях с поверхности образца вылетают струи ионов.

В связи с этим отметим, что время выделения струи ионов - $30 \mu \mathrm{s}$, т. е. на два порядка меньше, чем время колебаний исследуемого образца. Это показывает, что существует резервуар источников излучения, который исчерпывается за первые $30 \mu \mathrm{s}$. 


\section{Влияние размеров зерен кристаллов на динамику разрушения}

Какова же природа этого резервуара? Чтобы ответить на этот вопрос, обратимся снова к рис. 1. Как уже отмечалось, на поверхности образца наблюдаются кристаллические зерна, средний размер $L$ которых равен $\sim 30-50 \mu \mathrm{m}$. Границы между зернами, согласно [13-15], содержат большое количество дислокаций.

В работах $[11,12]$ показано, что при пересечении дислокаций возникают сильные искажения кристаллической решетки, которые под действием ударной волны могут вызывать распад межатомных связей и образование положительно заряженных ионов. Вероятно, плазма из положительно заряженных ионов кальция, кислорода и углерода вылетает из таких мест пересечения дислокаций.

Рассмотрим фрагмент временной зависимости интенсивности люминесценции (рис. 8). Она представляет со-

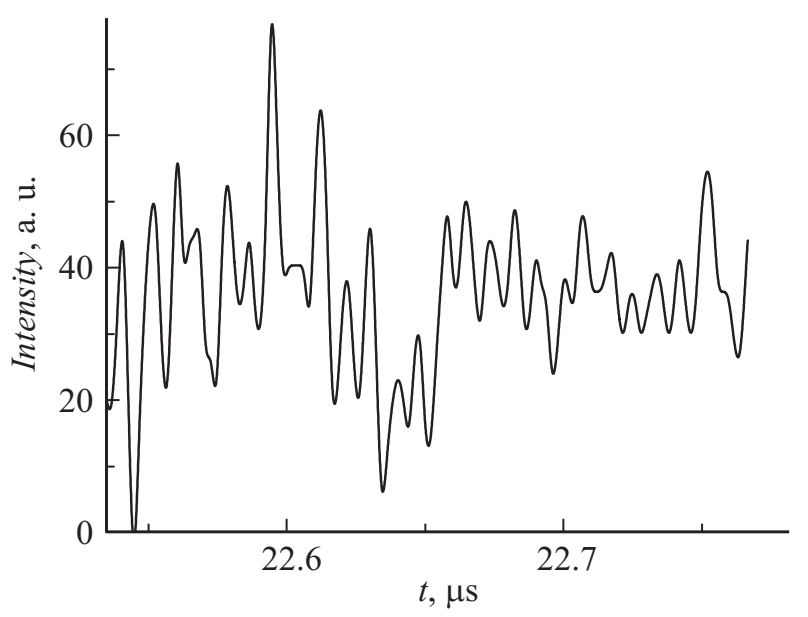

Рис. 8. Фрагмент временной зависимости интенсивности излучения ионов, вылетающих из кальцита в диапазоне от 22.3 до $22.8 \mu \mathrm{s}$.

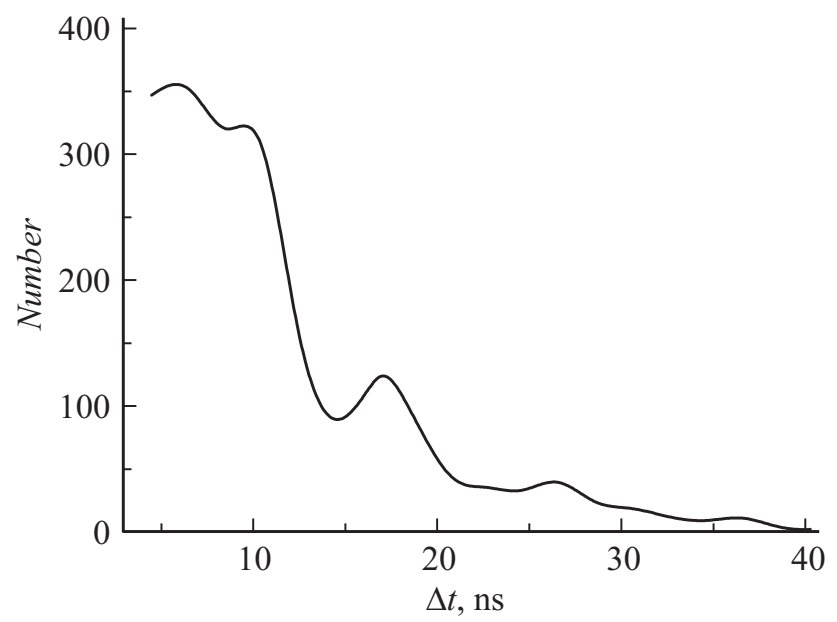

Рис. 9. Распределение интервалов времени между струями люминесценции. бой набор сильно перекрывающихся максимумов. Каждый из них, по-видимому, возникает при взаимодействии дислокаций, двигающихся в пересекающихся плоскостях скольжения. Тогда время, разделяющее появление максимумов, должно быть задано временем пробега $\tau$ ударной волной через зерна кристалла кальцита $\tau \approx L / v$, где $v$ - скорость ударной волны. Для оценки скорости ударной волны примем, что она близка к скорости продольных акустических колебаний, которая для кальцита равна $\sim 5 \mathrm{~km} / \mathrm{s}[16]$. Используя это значение и определенные с помощью микроскопа размеры кристаллических зерен, нашли, что $\tau \approx(6-10) \mathrm{ns}$.

На рис. 9 показано распределение интервалов времен между струями люминесценции. Видно, что это распределение имеет максимум в области $\sim(6-10)$ ns, положение которого хорошо согласуется с ожидаемым. Это показывает, что струи ионов действительно вылетают из граничных слоев между зернами кристаллов кальцита.

\section{Заключение}

Под действием ударной волны, вызванной электрическим разрядом, кристаллическая решетка кальцита распадается на положительно заряженные ионы кальция, углерода и кислорода.

Реализованы два случая. Первый - когда энергия разряда составляет $\sim 80 \mathrm{~J}$. В этом случае распадается более $60 \%$ объема образца. Второй случай, когда энергия разряда в 400 раз меньше - 0.2 J. Тогда ионы вылетают из мест сильных искажений кристаллической решетки около пересекающихся дислокаций в граничных слоях между кристаллическими зернами.

Работа выполнена при финансовой поддержке Российского фонда фундаментальных исследований (грант № 16-05-00138).

\section{Список литературы}

[1] Веттегрень В.И., Воронин А.В., Куксенко В.С., Мамалимов Р.И., Щербаков И.П. // ФТТ. 2014. Т. 56. Вып. 2. C. $315-317$.

[2] Веттегрень В.И., Щербаков И.П., Воронин А.В., Куксенко В.С., Мамалимов Р.И. // ФТТ. 2014. Т. 56. Вып. 5. C. $981-985$.

[3] Веттегрень В.И., Щербаков И.П., Куксенко В.С., Мамалимов Р.И. // ФТТ. 2014. Т. 56. Вып. 9. С. 1767-1771.

[4] Веттегрень В.И., Куксенко В.С., Щербаков И.П. // Физика Земли. 2016. № 5. С. 134-149.

[5] Щербаков И.П., Веттегрень В.И., Мамалимов Р.И., Махмудов Х. // ЖТФ. 2017. Т. 87. Вып. 8, в печати.

[6] Щербаков И.П., Веттегрень В.И., Мамалимов Р.И., Махмудов Х.Ф. // ФТТ. 2017. Т. 59. Вып. 7, в печати.

[7] Абрамова К.Б., Щербаков И.П., Русаков А.И. // ЖТФ. 1999. Т. 69. Вып. 2. С. 137-140.

[8] Веттегрень В.И., Куксенко В.С., Щербаков И.П. // ЖТФ. 2013. Т. 83. Вып. 1. С. 144-147. 
[9] Зайдель А.Н., Прокофьев В.К., Райский С.М., Славный B.A., Щрейдер Е.Я. Таблицы спектральных линий. Изд. 4. М.: Наука. 1977. 800 с.

[10] Stark J. // Annalen der Physik. 1914. Vol. 43. P. 965-983.

[11] Zakrevskii V.A., Shuldiner A.V. // Phil. Mag. B. 1995. Vol. 71. N 2. P. $127-138$.

[12] Закревский В.А., Шульдинер А.В. // ФТТ. 2000. Т. 42. Вып. 2. C. 263-266.

[13] Götze C., Kohlstedt D.L. // Contrib. Mineral. Petrol. 1977. Vol. 59. P. 293-306.

[14] De Bresser J.H.P. // J. Geophys. Research. 1996. Vol. 101. N B10. P. 22189-22201.

[15] Passchier C.W., Trouw R.A.J. Microtectonics. 2nd, Revised and Enlarged Ed. Springer, Berlin, Heidelberg, NY. 366 p.

[16] Schön J.H. Physical Properties of Rocks. Amsterdam: Elsevier, 2011. 480 p. 